\title{
Effect of microstructure on fatigue behaviour of advanced high strength ductile cast iron produced by quenching and partitioning process
}

André Caetano Melado ${ }^{1}$, Arthur Seiji Nishikawa ${ }^{1}$, Hélio Goldenstein ${ }^{1}$, Michael A. Giles ${ }^{2 *}$, Philippa A.S. Reed $^{2}$

${ }^{1}$ University of São Paulo, Brazil; ${ }^{2}$ University of Southampton, United Kingdom

*M.Giles@southampton.ac.uk

Keywords: Fatigue; Ductile iron heat treatment; Retained austenite; Quenching and partitioning; Austenite stability

Abstract

The fatigue behaviour of high strength ductile cast iron produced by a quenching and partitioning process (Q\&P) is evaluated. The Q\&P process is receiving increased attention as a new way to produce ultra-high strength steels with multiphase microstructures composed of a martensite matrix and substantial amounts of carbon-stabilized retained austenite. Currently, the mechanical properties arising from applying the Q\&P process in ductile cast irons have not been investigated. Thermal treatments consisted of heating the material to $880^{\circ} \mathrm{C}$ for a 2 hour soaking time followed by quenching in oil at $140^{\circ} \mathrm{C}$ and $170^{\circ} \mathrm{C}$, intermediate temperatures between $\mathrm{M}_{\mathrm{s}}$ and $\mathrm{M}_{\mathrm{f}}$ allowing the formation of a controlled amount of athermal martensite. The material was reheated to $300^{\circ} \mathrm{C}$ and $375^{\circ} \mathrm{C}$ (the partition treatment) for different times between 15 and 120 minutes and subsequently air-cooled to room temperature. Microstructural evolution and carbon partitioning was investigated by in situ synchrotron X-ray diffraction. With a microstructure composed of tempered martensite, bainitic ferrite and carbon-enriched stabilized austenite, a new class of properties was obtained, with an enhanced strength when compared to ADI (austempered ductile iron) while still maintaining reasonable elongation. Fatigue testing was undertaken using polished plain bend bars (no stress concentration features) assessed under four-point bending. Uninterrupted tests at varying loads show that the higher partitioning temperature is beneficial for fatigue life. Fracture initiation sites are primarily from pores and a number of decohered graphite nodules. A strong influence of the microstructure on subsequent fatigue crack growth is observed from interrupted testing with replica records and SEM examination of tested samples, with cracks exhibiting significant tortuosity, at times even appearing to grow approximately parallel to the tensile axis. Using these results, the effects of the Q\&P treatment, particularly the role of the partitioning time and temperature, on the fatigue properties of ductile cast iron are assessed. 


\section{Introduction}

Ductile cast irons are an important class of engineering materials known for providing a good combination of mechanical properties with low production cost. Successful application of a material as a structural component requires optimization of its fracture toughness, fatigue resistance and yield strength and matrix modification by heat treatments has been applied in such alloys to improve their mechanical properties. For example, austempered ductile iron (ADI) has attracted interest due to an excellent combination of mechanical properties such as high yield and tensile strengths and good ductility. ADI is produced by an isothermal heat treatment known as austempering following on from austenitisation. The high silicon content of cast irons suppresses the precipitation of carbide during austempering and a substantial amount of stable austenite with a high carbon content is retained. The excellent properties of $A D I$ are related to its unique microstructure that consists bainitic ferrite and the carbon enriched austenite, which is termed ausferrite.

The quenching and partitioning (Q\&P) process has been utilized as a new (potentially lower cost) route to produce steels with substantial amounts of retained austenite. The microstructure is composed of a martensite matrix and substantial amounts of carbon-stabilized retained austenite. Martensite confers high strength, while stabilized austenite favours good ductility $[1,2,3]$.

The process consists of a two-step heat treatment. After austenitisation (complete or partial), the steel sample is quenched to a temperature between $M_{s}$ and $M_{f}$ to produce a controlled mixture of martensite and austenite. Then, in the so-called partitioning step, the material is isothermally held at a partitioning temperature above the quenching temperature to allow the carbon to partition from the martensite into the austenite, stabilizing it at room temperature. Figure 1 shows a schematic of the Q\&P process.

Recent research $[4,5,6,7,8]$ has shown that the Q\&P process when applied to ductile iron produces material with significantly higher tensile strength whilst retaining satisfactory ductility. The unique mechanical properties, when compared with several classes of ductile iron found in the literature

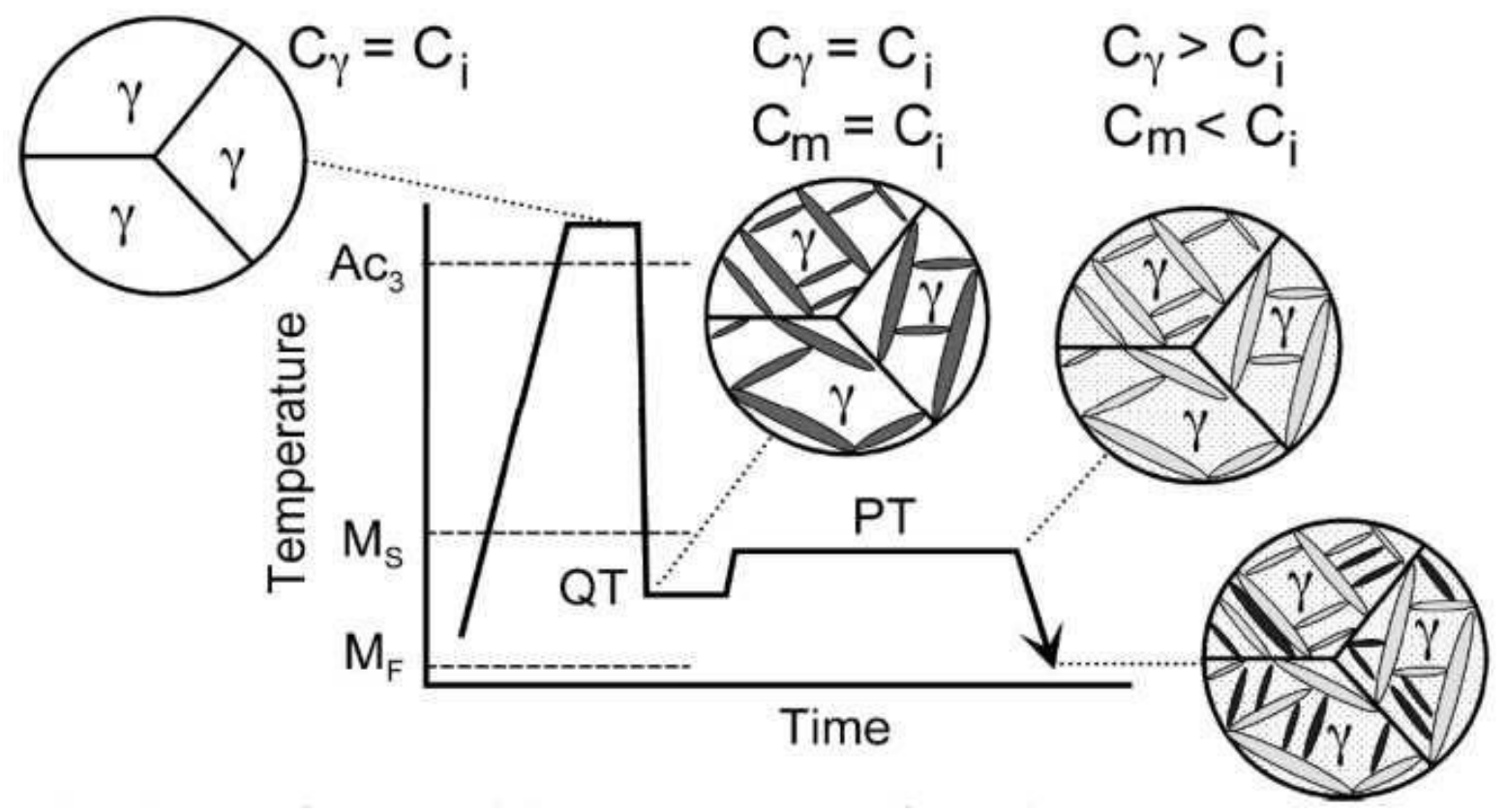

Figure 1: Schematic diagrams of the Q\&P process, which obtains ferrite/austenite/martensite microstructures from the decomposition of homogenous austenite. $\mathrm{Ci}, \mathrm{C} \gamma$ and $\mathrm{Cm}$ represent the carbon contents of the initial alloy, austenite and martensite respectively. QT and PT are the quenching and partitioning temperatures respectively [3]. 


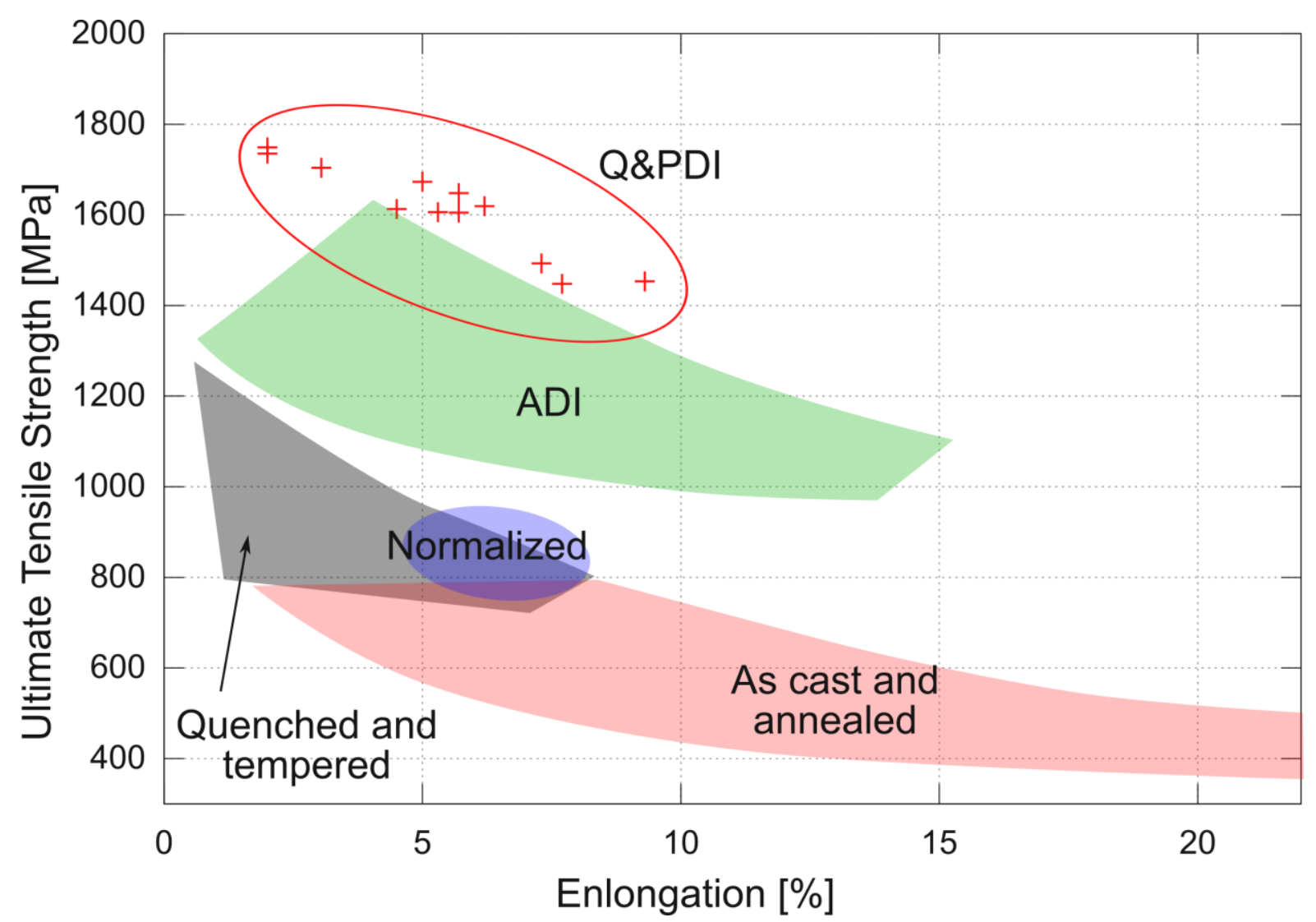

Figure 2: Mechanical properties comparison between ductile iron classes. Adapted from [33].

(Figure 2), show that this material can be classified as a new class of ductile iron, quenched and partitioned ductile iron (Q\&PDI).

There is little literature examining the fatigue properties of Q\&PDIs. However, the effects of the quenching and partitioning process on fatigue behaviour of other steels and the effects of similar heat treatments on ductile irons provide some relevant background. For example, studies of ADI provide useful insight as they are also cast irons (and so will have similar compositions), and retained austenite appears to play a prominent role in determining the mechanical properties. Furthermore the heat treatment is somewhat similar to the Q\&P process, consisting of austenitisation followed by quenching to a temperature of around $250-400^{\circ} \mathrm{C}$ with a subsequent isothermal hold (austempering) at that temperature [9]. The process window for austempering is limited by the formation of undesirable $\varepsilon$-carbide [10] and austempering times are typically around 1-4 hours long [11].

While stress induced transformation of austenite is a well-known phenomenon, the effect on fatigue behaviour has been disputed. For example, retained austenite fractions have been observed to improve fatigue performance in Q\&P steels [12] and ADI [13]. This is attributed to the transformation of austenite into martensite ahead of the crack tip. In particular, closure effects due to roughness caused by propagation along martensite lath boundaries $[14,15]$ are cited or strain energy absorption (even when crack closure is reduced c.f. a heat treatment resulting in a ferrite-martensite matrix [16]) both of which are claimed to decrease the crack propagation rates.

With the decrease in propagation rates attributed to the local transformation of RA, it has however been observed that bulk transformation in TRIP steels at low plastic strain amplitudes is detrimental to the overall fatigue life [17]. In this study, better fatigue performance was observed in a steel with smaller RA grains, which are more stable to martensite formation. Conversely, it has also been 
suggested that retained austenite must not be too stable to resist local plasticity induced transformation [12]. The balance in fatigue behaviour outcomes clearly depends on whether local transformations at the crack tip affect crack tip micromechanics beneficially, or whether overall/bulk transformations exhibit worse overall lifetimes due to higher overall proportions of martensite (which usually has reduced ductility and worse fatigue performance). In ADI, HCF rotating bending tests were carried, and increased fatigue lives were noted with increased levels of retained austenite. In the ADI with the increased RA fraction, the larger, blocky RA grains had lower carbon contents and had been stabilised by segregation of additional $\mathrm{Mn}$ and $\mathrm{Mo}$ to the intercellular regions. Here the RA may be acting as local ductile microstructure regions-not necessarily transforming to martensite at all.

With the stability of retained austenite (as well as its local distribution) apparently critical to fatigue performance, possibly more so than the quantity of RA [18], it appears that an optimal stability in conjunction with an appropriate RA distribution is necessary for good fatigue performance. As has already been noted, larger RA grains are less stable. Additionally, the RA morphology affects the stability; with more equiaxed RA reported as transforming more readily than a lamellar structure [19, 20]. Furthermore, surrounding phases also influence the stability of RA somewhat indirectly by affecting transmission of strain, i.e. a harder surrounding phase reduces the strain transmitted to the austenite, reducing its potential for transformation $[19,21]$. For example, RA surrounded by bainite is likely to be more stable than RA surrounded by softer ferrite. This study therefore aims to elucidate further how the Q\&P process affects the formation, distribution and relative proportions of phases in an $A D I$ and how this affects the final mechanical properties, including the fatigue performance. Insight into the factors affecting the micromechanics of fatigue will allow further tuning and optimisation of the Q\&P process.

\section{Materials and Experimental Methods}

\subsection{Material Characterisation}

The ductile iron studied in this work was supplied by Tupy S.A foundry from Brazil as-cast Y-blocks processed with in mould inoculation to provide a high nodule count. The chemical composition was 3.47C-2.47Si-0.20Mn-0.38Cu (in wt.\%) and the nodule count was above 400 nodules $/ \mathrm{mm}^{2}$. The relatively low manganese content $(0.20 \mathrm{wt} . \%)$ and high nodule count were intentionally employed, in order to minimize microsegregation, as described in previous work [4].

The martensite start temperature $\left(\mathrm{M}_{\mathrm{s}}\right)$ was determined using a Bähr DIL 805A quenching dilatometer and was approximately $230^{\circ} \mathrm{C}$ (Figure 3 ). To evaluate the volumetric fraction of transformed martensite during quenching step, the model proposed by Kostinen-Marburger [22] was used as follows:

$$
f\left(\alpha^{\prime}\right)=1-\exp \left[-1.10 \times 10^{-2}\left(M_{S}-T_{q}\right)\right]
$$

where $f\left(\alpha^{\prime}\right)$ is the transformed fraction of martensite at the quenching temperature $T_{Q}$.

For the Q\&P heat treatment, samples were austenitised at $880^{\circ} \mathrm{C}$ for $2 \mathrm{~h}$ followed by quenching in oil at $140^{\circ} \mathrm{C}$ and $170^{\circ} \mathrm{C}$ (approximately, 60 and $45 \%$ of transformed martensite, respectively). For the next step the material was reheated to $300^{\circ} \mathrm{C}$ and $375^{\circ} \mathrm{C}$ (partitioning treatment) for different times between 15 and 120 minutes and subsequently air-cooled to room temperature. In situ X-ray diffraction was performed in the samples, providing real time information of phase evolution and lattice parameter changes during the Q\&P process. The experiments were carried out at the XTMS installation of the Brazilian Nanotechnology Laboratory (LNNano) located in the XRD1 synchrotron beam line at Brazilian Synchrotron Light Laboratory (LNLS). The experimental setup consisted of a 
custom built Gleeble 3550 thermo-mechanical simulator integrated with a synchrotron monochromatic X-ray beam at $12 \operatorname{keV}(\lambda=1.0332 \AA)$ incident on the sample.

Room temperature X-ray diffraction, performed with a Brucker diffractometer model D8 Phaser at room temperature, was also performed in samples to evaluate the final microstructure. Volume fractions of the individual phases were quantified by comparing the integrated intensities of $(111) \mathrm{Y}$, $(110) \alpha,(200) \gamma$ and $(200) \alpha$ diffraction peaks with their theoretical intensities [23]. The carbon concentration in austenite $(\mathrm{wt} . \% \mathrm{C})$ was evaluated from the measured lattice parameter, using the empirical Dyson and Holmes [24] equation (Equation 2).

$$
a_{\gamma}=3.5780+0.033 C_{\gamma}+0.00095 M n_{\gamma}+0.0015 C u_{\gamma}
$$

\subsection{Baseline Mechanical Testing}

Baseline mechanical properties were obtained using for each Q\&PDI. Tensile testing was performed using an EMIC DL10000 universal testing machine according to ASTM A370. Charpy impact tests in accordance with ASTM E23 were conducted on unnotched specimens in order to evaluate the process window of each proposed heat treatment. Rockwell hardness (HRC) testing and Vickers microhardness testing was carried out using a Shimadzu HMV Micro Hardness Tester using a load of $0.3 \mathrm{kgf}$ (HV0.3).

\subsection{Fatigue Testing}

Fatigue testing was carried out under four-point bend load control testing. Total life tests and interrupted tests were performed on polished plain bend bar (PBB) specimens measuring $10 \mathrm{~mm} \times 10 \mathrm{~mm} \times 75 \mathrm{~mm}$. Bending tests have simple geometries and four-point bending was chosen as it is hoped that this makes it more likely to capture initiation at a significant defect and thereby identify the significant features for crack initiation. In contrast, three-point bending has a stress distribution where the tensile stress at the surface decreases moving away from the central roller and crack initiation is encouraged above the roller.

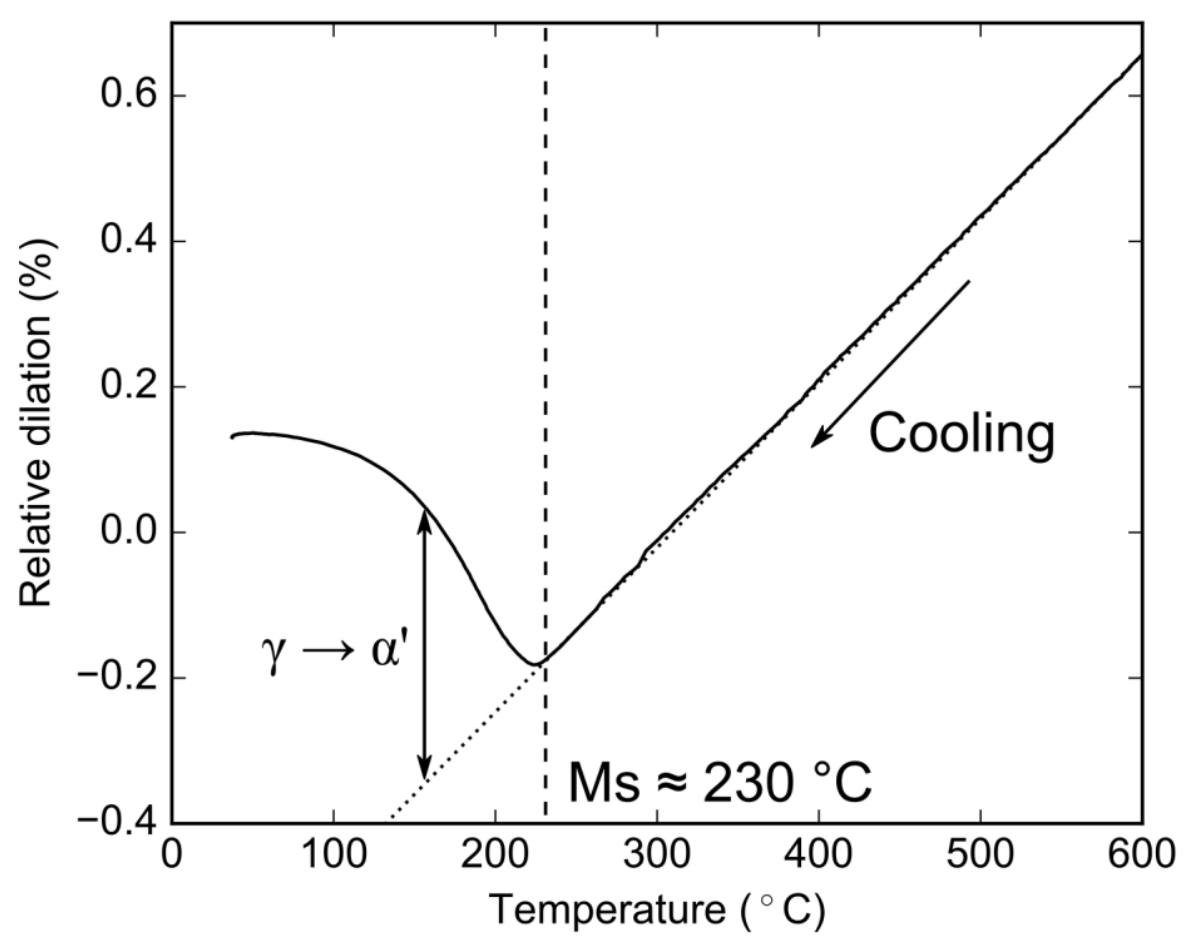

Figure 3: Dilatometry test to determine the martensite start temperature. 
These tests were performed at room temperature in air on a digitally controlled Instron 8501 servohydraulic machine. The maximum applied top surface stresses were varied between 400 to $800 \mathrm{MPa}$, at an $\mathrm{R}=0.1$ and a frequency of $20 \mathrm{~Hz}$. During the interrupted tests, replicas were taken using Struers Repliset-F5 to assess the initiation and growth processes of short cracks.

\section{Results and discussion}

\subsection{Microstructure}

The final microstructure of the Q\&P ductile iron (Figure 4) presented martensite (leaf-like plates with midrib) and bainitic ferrite associated with austenite (ausferrite). Due to the low levels of alloying elements and high inoculation level, no primary carbides were found in the microstructure of the material.

Figure 5 shows the evolving volume fraction of austenite and carbon content in the austenite obtained by X-ray diffraction in-situ during the partitioning heat treatment. It can be seen that with a partitioning temperature of $300^{\circ} \mathrm{C}$ the transformation of the austenite to bainitic ferrite occurs more slowly. The carbon enrichment of the austenite is also slower at the partitioning temperature of $300^{\circ} \mathrm{C}$.
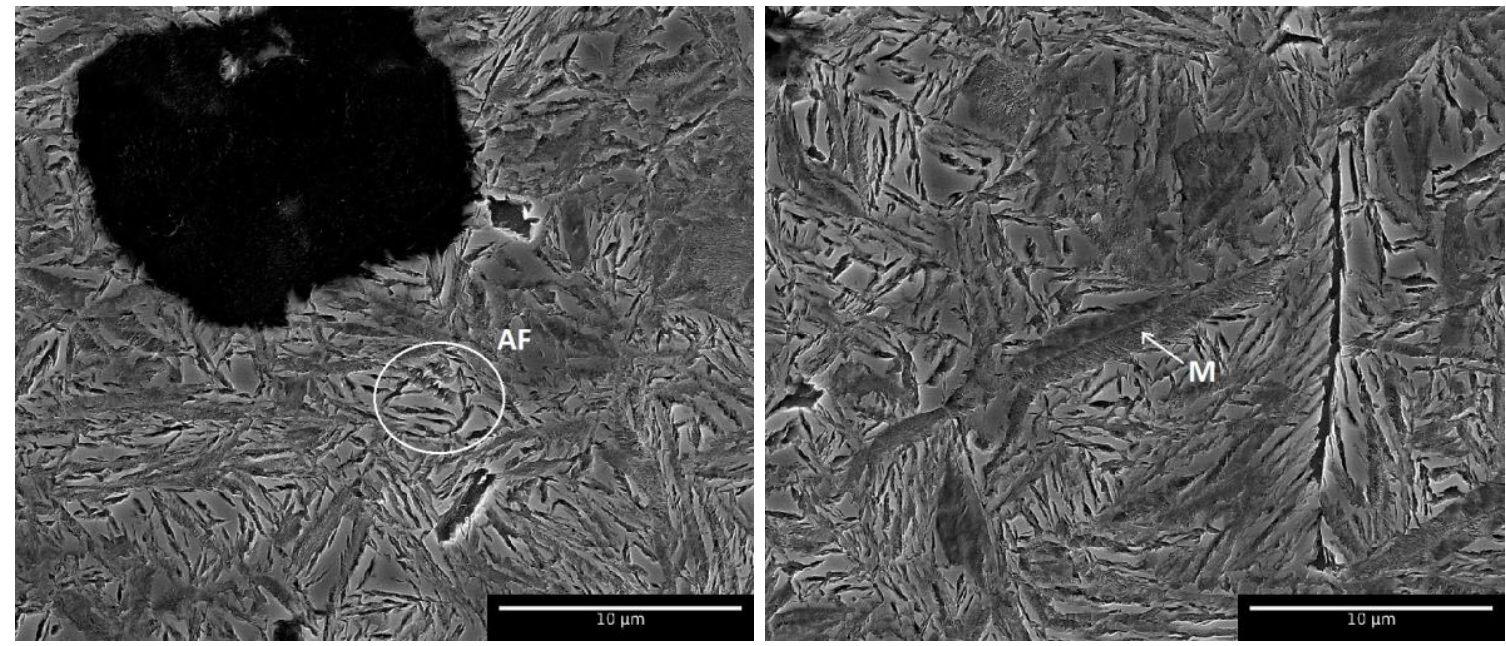

Figure 4: Microstructure of the Q\&PDI quenched at $170^{\circ} \mathrm{C}$ and partitioned at $375^{\circ} \mathrm{C}$ for 15 minutes. AF: ausferrite (austenite and bainitic ferrite), $M$ : partitioned martensite.
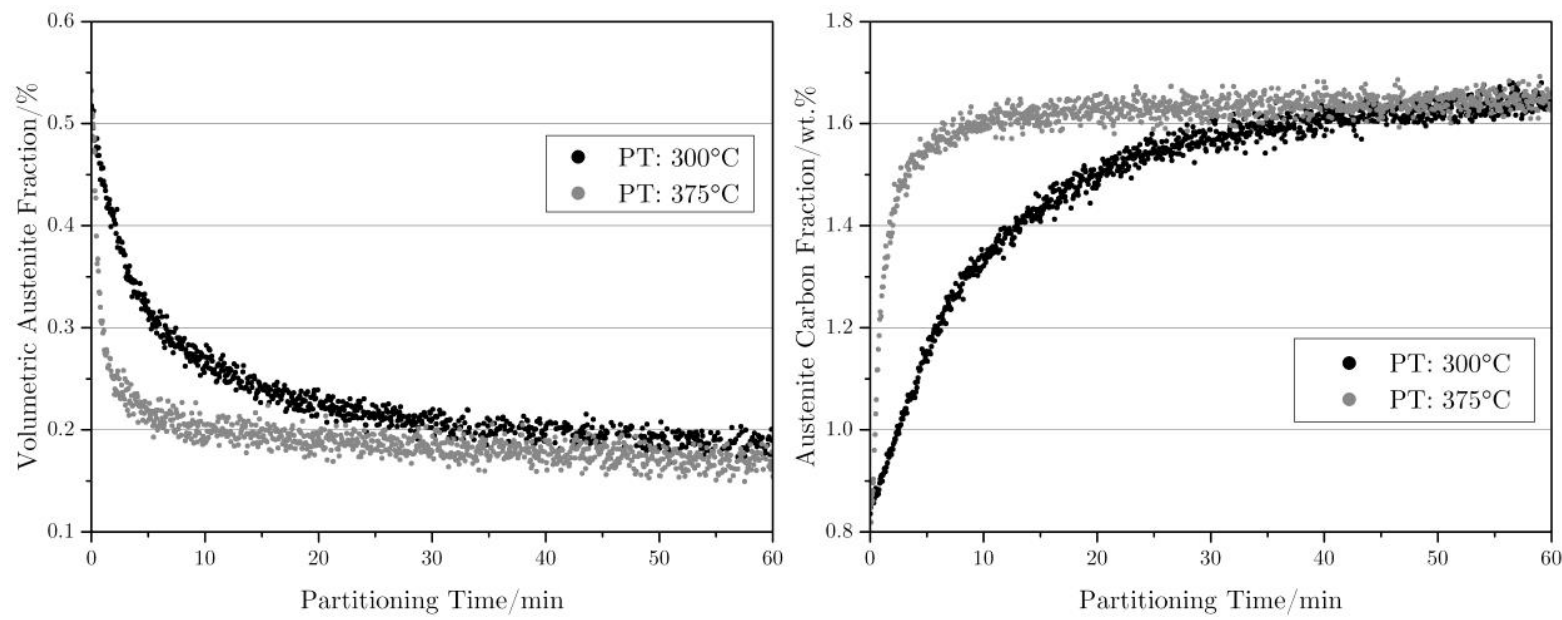

Figure 5: In situ x-ray results for samples quenched at $170^{\circ} \mathrm{C}$. (a) austenite volume fraction evolution during partitioning, (b) austenite carbon content evolution during partitioning. 
As can be seen in Figure $5 \mathrm{a}$, after 15 minutes at $300^{\circ} \mathrm{C}$ the volume fraction of austenite measured in situ (at the transformation temperature) is approximately $25 \%$, but the value measured after cooling, at room temperature, was $18 \%$, as shown in Table 3. It can be inferred that the missing austenite $(7 \%)$ transformed into untempered martensite during cooling after the partitioning step, due to its low carbon concentration. The carbon content of austenite after the partitioning time of 15 minutes at $300^{\circ} \mathrm{C}$ of samples quenched at $170^{\circ} \mathrm{C}(170 / 300)$ was approximately $1.36 \%$, while the samples $170 / 375$ showed a carbon content of $1.55 \%$ after the same partitioning time.

\subsection{Mechanical Properties}

Hardness and tensile test results of the Q\&P treated samples for each condition used in this work are presented in Table $1[6,7]$. The results presented in Table 1 show that the Q\&P process applied to ductile iron produces a material with high tensile strength and satisfactory ductility.

Partitioning times of 15 minutes (except for a variation of the 170/300 condition which was carried out for time of 2 hours), were chosen based on these previously reported $[6,7]$ impact test results,

Table 1: Summary of mechanical properties.

\begin{tabular}{ccccccc}
\hline $\begin{array}{c}\text { Quenching/Partitioning } \\
\text { Temperature }\left({ }^{\circ} \mathbf{C}\right)\end{array}$ & $\begin{array}{c}\text { Partitioning } \\
\text { Time (min) }\end{array}$ & $\begin{array}{c}\text { UTS } \\
(\mathbf{M P a})\end{array}$ & $\begin{array}{c}\text { Yield } \\
\text { Strength } \\
(\mathbf{M P a})\end{array}$ & $\begin{array}{c}\text { Elongation } \\
(\%)\end{array}$ & $\begin{array}{c}\text { Hardness } \\
\text { (HRC) }\end{array}$ & $\begin{array}{c}\text { Micro- } \\
\text { hardness } \\
\text { (HV0.3) }\end{array}$ \\
\hline \multirow{2}{*}{$\mathbf{1 4 0 / 3 0 0}$} & 15 & 1704 & 1580 & 3.1 & $50.1 \pm 0.32$ & $659 \pm 23.95$ \\
& 60 & 1735 & 1629 & 2.0 & $49.6 \pm 0.42$ & $644 \pm 19.54$ \\
& 120 & 1749 & 1641 & 2.4 & $50.5 \pm 0.18$ & $630 \pm 11.78$ \\
$140 / 375$ & 15 & 1606 & 1490 & 5.3 & $45.8 \pm 0.27$ & $557 \pm 19.48$ \\
& 60 & 1605 & 1520 & 5.7 & $46.3 \pm 0.43$ & $579 \pm 18.32$ \\
& 120 & 1613 & 1542 & 4.5 & $46.2 \pm 0.35$ & $592 \pm 11.18$ \\
$170 / 300$ & 15 & 1673 & 1505 & 5.0 & $48.7 \pm 0.11$ & $630 \pm 15.77$ \\
& 60 & 1648 & 1480 & 5.7 & $48.8 \pm 0.30$ & $618 \pm 22.31$ \\
& 120 & 1619 & 1456 & 6.2 & $48.4 \pm 0.46$ & $626 \pm 11.51$ \\
$170 / 375$ & 15 & 1453 & 1300 & 9.3 & $45.1 \pm 0.37$ & $522 \pm 17.02$ \\
& 60 & 1448 & 1326 & 7.7 & $44.3 \pm 0.19$ & $553 \pm 17.11$ \\
& 120 & 1493 & 1392 & 7.3 & $44.8 \pm 0.29$ & $560 \pm 9.02$ \\
\hline
\end{tabular}

a)

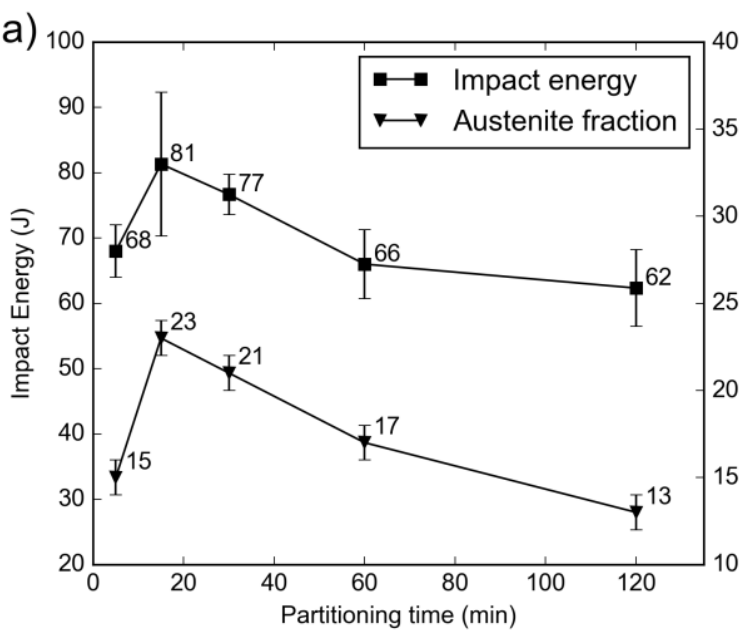

b)

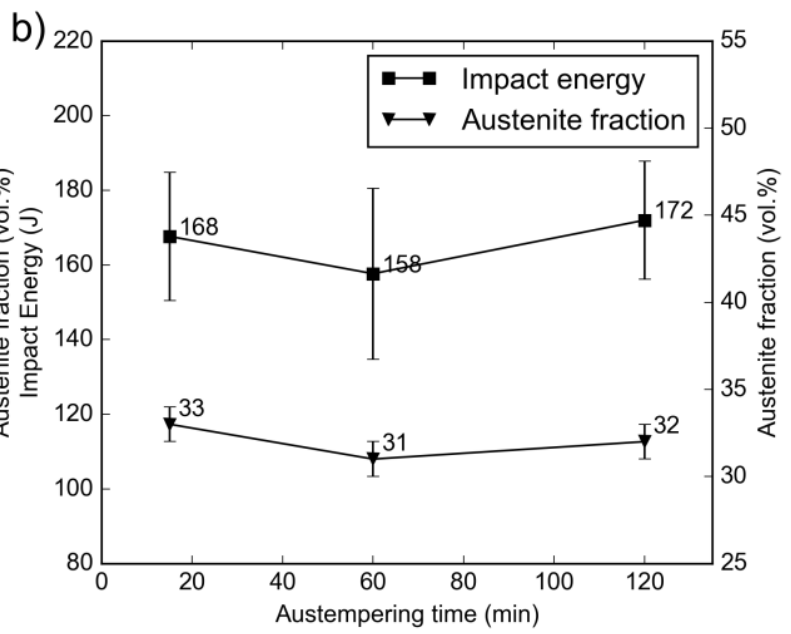

Figure 6: Impact energy and volumetric fraction of austenite as a function of partitioning time for (a) the 170/375 Q\&PDI condition and (b) an $A D I$ austempered at $375^{\circ} \mathrm{C}$. 


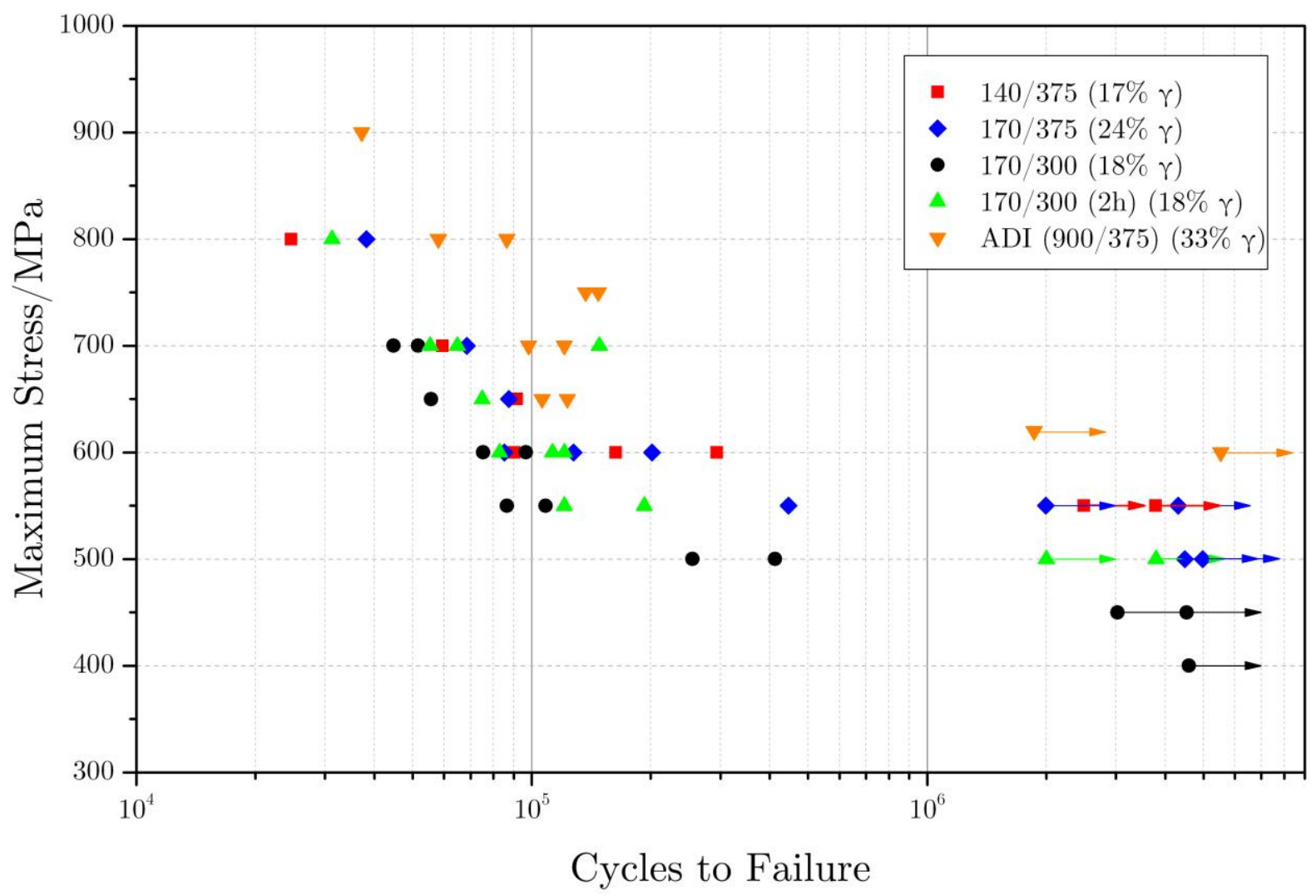

Figure 7: Total life results compared on the basis of maximum applied stress. All samples that lasted longer than $10^{6} \mathrm{cycles}$ were unbroken at the end of the test.

which showed that with partitioning temperatures of $375^{\circ} \mathrm{C}$, the impact energy decreased for samples partitioned for over 15 minutes (first seen in samples partitioned for 30 minutes) (Figure 6). The reduction of impact properties indicates the end of the process window when austenite with a high carbon content decomposes into ferrite and cementite, degrading the mechanical properties $[11,12$, 13].

Using the same chemical composition, an ADI was also produced to compare with the Q\&PDIs. The comparison $A D I$ samples were austempered at $375^{\circ} \mathrm{C}$ for 15 minutes. The mechanical properties of the comparison ADI are shown in Table 2. Compared with the Q\&PDIs, the ADI has higher ductility and impact energy but lower strength, as would be expected given the increased retained austenite fraction and less refined microstructure.

Table 2: Properties of the ADI produced for comparison with the Q\&PDIs.

\begin{tabular}{cccccccc}
\hline $\begin{array}{c}\text { Yield } \\
\text { Strength/MPa }\end{array}$ & UTS/MPa & Elongation/\% & $\begin{array}{c}\text { Impact } \\
\text { Energy/J }\end{array}$ & $\begin{array}{c}\text { Hardness } \\
\text { (HRC) }\end{array}$ & $\begin{array}{c}\text { Micro- } \\
\text { hardness } \\
\text { (HV0.3) }\end{array}$ & v/wt.\% & $\begin{array}{c}\text { wt.\% } \\
\text { C in v }\end{array}$ \\
\hline 735 & 1008 & 14 & 168 & $33.2 \pm 0.22$ & $391 \pm 17.01$ & 33 & 1.6 \\
\hline
\end{tabular}




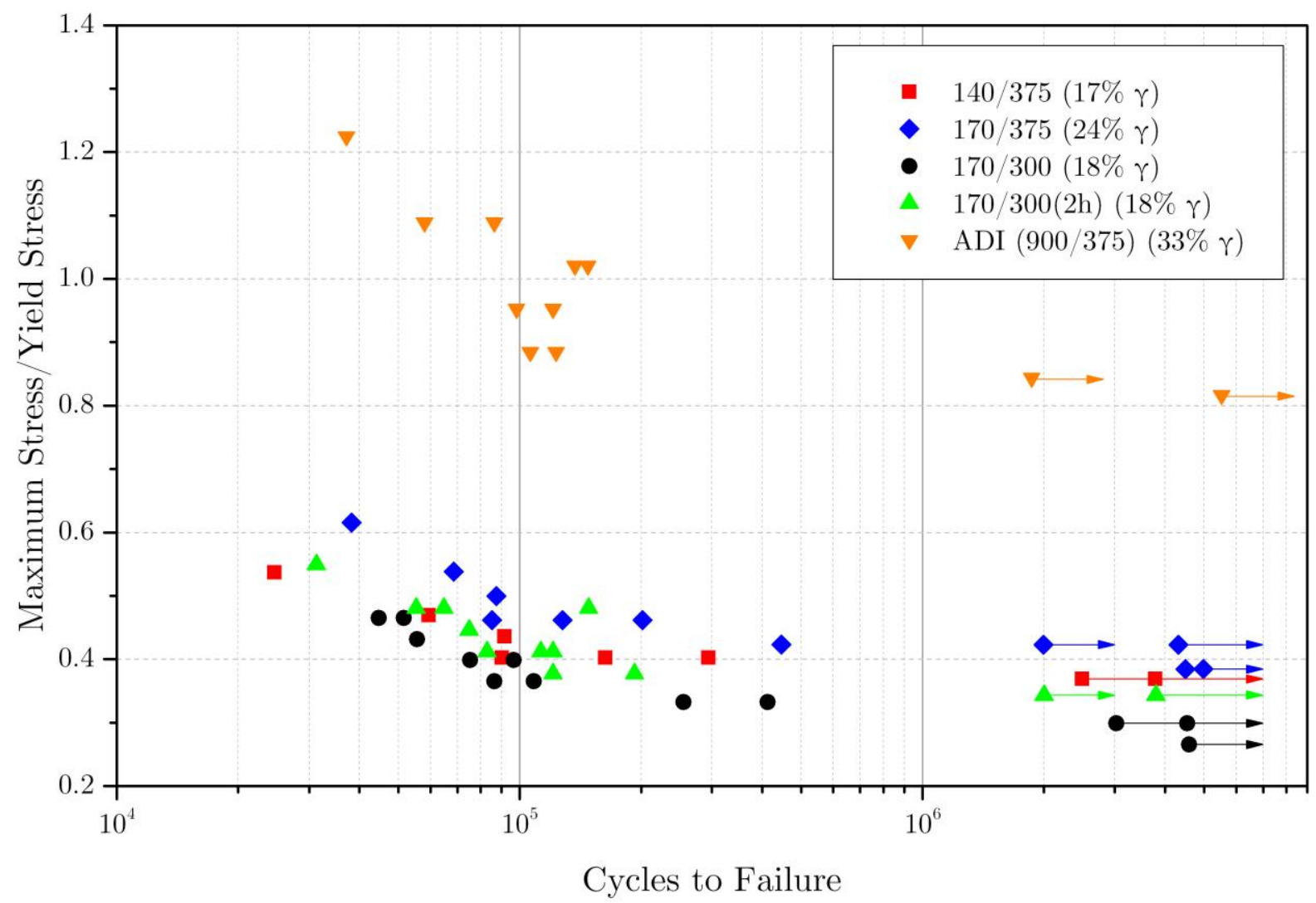

Figure 8: Total life results compared on the basis of maximum applied stress normalised by each condition's yield stress. All samples that lasted longer than $10^{6}$ cycles were unbroken at the end of the test.

\subsection{Total Life Testing}

Typical fatigue behaviour is observed; increasing lifetime is seen with a decrease in applied stress range for all the materials tested (Figure 7). The fatigue behaviour is in broad agreement with behaviour reported by Stokes et al [22] for different types of ADI under the same fatigue test conditions. The yield strength of ADI tested by Stokes et al. ranged from approximately $650 \mathrm{MPa}$ to $1170 \mathrm{MPa}$, and observed fatigue limits (in terms of maximum applied bending stress at the surface) ranged from $250 \mathrm{MPa}$ to $500 \mathrm{MPa}$. In the Q\&PDIs tested here, the yield strength ranged from $1300 \mathrm{MPa}$ to $1500 \mathrm{MPa}$ and fatigue limits ranged from $450 \mathrm{MPa}$ to $550 \mathrm{MPa}$. The fatigue limits scale effectively with yield strength. By comparison the fatigue strength of the austempered condition appears to be in excess of $600 \mathrm{MPa}$.

To allow for the expected effect of differing yield stress, the fatigue lives were also compared in terms of the applied fraction of yield stress (Figure 8). From Figure 8 it can be seen that, on this basis, the ADI was often being tested close to or even beyond its yield strength. The response of the Q\&PDIs in relation to their yield stresses is very different.

This is a useful distinction to observe as considering the lifetimes in terms of the fraction of yield achieved allows comparison of the materials in terms of expected relative local plastic strain levels. This recognises to some extent that the phases in the microstructure have different local properties, and that it is the local accumulation of strain that will control fatigue initiation. By normalising for the (expected) differences in fatigue behaviour due to the yield strength changes, the way the balance of 
phases may affect crack initiation and growth processes can be investigated in more detail, particularly the austenite volume fractions and expected C-levels (stability levels) in the RA. In Figure 8, the difference between the different Q\&P heat treatments in terms of fatigue performance can be more clearly elucidated (as the effect of yield strength variation has been accounted for) and the proportions of retained austenite are also indicated for each heat treatment.

Both the slightly better performance of the 140/375 condition over the other Q\&PDI conditions and the overall superior performance of the ADI suggest that the austenite phase may be accommodating local plastic strain more effectively. However, with such a difference between the ADI and the Q\&PDI conditions it is likely that it is not solely the fraction of the retained austenite that is responsible.

The highest fatigue limits in the Q\&PDIs were found in the materials partitioned at $375^{\circ} \mathrm{C}$, with the highest fatigue limit shown by the heat treatment $170 / 375$ which can be linked to the high percentage of retained austenite (24\%) as can be seen in Table 3. Another factor is related to the partitioning temperature. Higher partitioning temperature favours, by diffusion, the reduction of carbon supersaturation in martensite phase through partition to the remaining austenite and the precipitation of transition carbides inside the martensite plates. Toji et.al [23] found that carbon partitioning to austenite from supersaturated martensite in medium and high carbon steels is accompanied by the precipitation of transition carbides. The hardness of the materials partitioned at $300^{\circ} \mathrm{C}$ are relatively higher than those partitioned at $375^{\circ} \mathrm{C}$ (Table 1 ). This indicates a martensite with a high carbon supersaturation, which we expect to be harder and more brittle and so more deleterious to crack initiation processes and crack growth resistance. The lowest fatigue resistance was found in the 170/300 heat treatment with a partitioning time of 15 minutes. Another factor is the expected formation of fresh martensite, from austenite with low carbon concentration, in the cooling after the partitioning step.

Table 3: Calculated austenite fraction and carbon content within the austenite phase at room temperature.

\begin{tabular}{cccccc}
\hline $\begin{array}{c}\text { Quenching/Partitioning } \\
\text { Temperature }\left({ }^{\circ} \mathbf{C}\right)\end{array}$ & $\begin{array}{c}\text { Partitioning } \\
\text { Time (min) }\end{array}$ & $\begin{array}{c}\text { Yield Strength } \\
\text { (MPa) }\end{array}$ & $\begin{array}{c}\text { Impact } \\
\text { Energy }(\mathrm{J})\end{array}$ & $\begin{array}{c}\text { Austenite } \\
(\%)\end{array}$ & $\begin{array}{c}\text { wt.\% C } \\
\text { in Y }\end{array}$ \\
\hline $\mathbf{1 4 0 / 3 7 5}$ & 15 & 1490 & 44.9 & 17 & 1.54 \\
\hline $\mathbf{1 7 0 / 3 0 0}$ & 15 & 1505 & 61.1 & 18 & 1.36 \\
\hline $\mathbf{1 7 0 / 3 0 0}$ & 120 & 1456 & 70.2 & 18 & 1.63 \\
\hline $\mathbf{1 7 0 / 3 7 5}$ & 15 & 1300 & 81.2 & 24 & 1.55 \\
\hline
\end{tabular}

\subsection{Crack Initiation and propagation}

Predominantly, the initiation of the dominant fatigue crack was seen to occur at casting defects such as porosities and shrinkages (Figure 9a and Figure 9b) and from the edge of the sample as the corner of the sample may act as a stress concentration (Figure $9 c$ and Figure $9 d$ ). In general, these defects have an angular morphology and clearly act as significant stress concentration areas. Cracks that appeared to initiate around graphite nodules frequently did not propagate significantly (as shown in the yellow box in Figure 10c). This is in contrast to other work where graphite nodules acted as more significant crack initiation features [9] . It should be noted that the graphite nodules here were considerably smaller than in some other studies, in part due to requirements to control microsegregation in the casting to allow the Q\&P heat treatment process to be successful.

Crack propagation processes appeared to consist of significant amounts of crack coalescence (Figure $10 \mathrm{a}$ and Figure 10b), explaining some of the tortuosity of the main (fatal) cracks. A larger number of cracks and hence a greater deflection of the final dominant crack path were observed at higher applied stresses. 
Crack path tortuosity can also be attributed to the presence of Widmanstätten ferrite (Figure 11). Due to low alloying element content, the ductile iron exhibited low hardenability, i.e., during the quenching step, proeutectoid ferrite can be formed. The presence of this proeutectoid ferrite was found in the Q\&PDI microstructure. This ferrite morphology is known to produce a weak film at prior austenite grain boundaries and this indicates that the fatigue crack growth has occurred through this weakest region [25] as shown in Figure 11.

Further initiation and subsequent propagation has also been observed within martensite plates as can be seen in Figure 12. Even after the partitioning step, the martensite will exhibit high hardness indicating a high carbon content mainly for those samples partitioned at lower temperatures.

In order to study the crack propagation behaviour more quantitatively, projected crack lengths perpendicular to the applied tensile axis were measured from micrographs of the replica record. To compare crack propagation rates, the changes in surface crack length were related to $\Delta \mathrm{K}$ using the equations by Scott and Thorpe [26] for semi-elliptical (surface breaking) cracks. Where cracks initiated at the corner of the sample, the equations for a quarter-elliptical corner crack given by Newman and Raju [27] were used.

Where cracks were observed to coalesce on the replica record, they are subsequently treated as if they instantly achieve their equilibrium crack aspect ratio as it is not possible to know exactly at what point between the discrete observations on the replica record that the coalescence event happened. Similarly, where a crack reaches the corner of the sample, it is treated as if it immediately assumes the quarter-elliptical shape with its equilibrium crack aspect ratio.

The crack aspect ratio $(a / c)$ for each data point was estimated by finding the $a / c$ value for which the stress intensity factor ranges along the surface and at the deepest point were equal (for the measured projected crack length c). In general, the crack aspect ratio was seen to decrease (i.e. the crack becomes shallower) as the crack length increases, a commonly observed result in bending as the crack approaches the neutral axis and the stress gradient increases with the decreasing uncracked ligament [26]. Coalescence may also contribute to a decrease in aspect ratio for longer crack lengths [28].

The crack growth rates during crack propagation for samples tested at a maximum surface stress of $600 \mathrm{MPa}$ are compared in Figure 13. Generally, propagation rates appear to be quite similar between the Q\&PDIs, although in comparison the ADI (with the highest retained austenite level) does show the best crack propagation resistance. When considering the effect of retained austenite observed in other studies, it is perhaps surprising that the 170/375 does not show a more significantly reduced crack growth rate amongst the Q\&PDIs, given its increased retained austenite fraction. However, this was not observed, and it should be noted that the relative differences in retained austenite with the Q\&PDIs was not very great. 

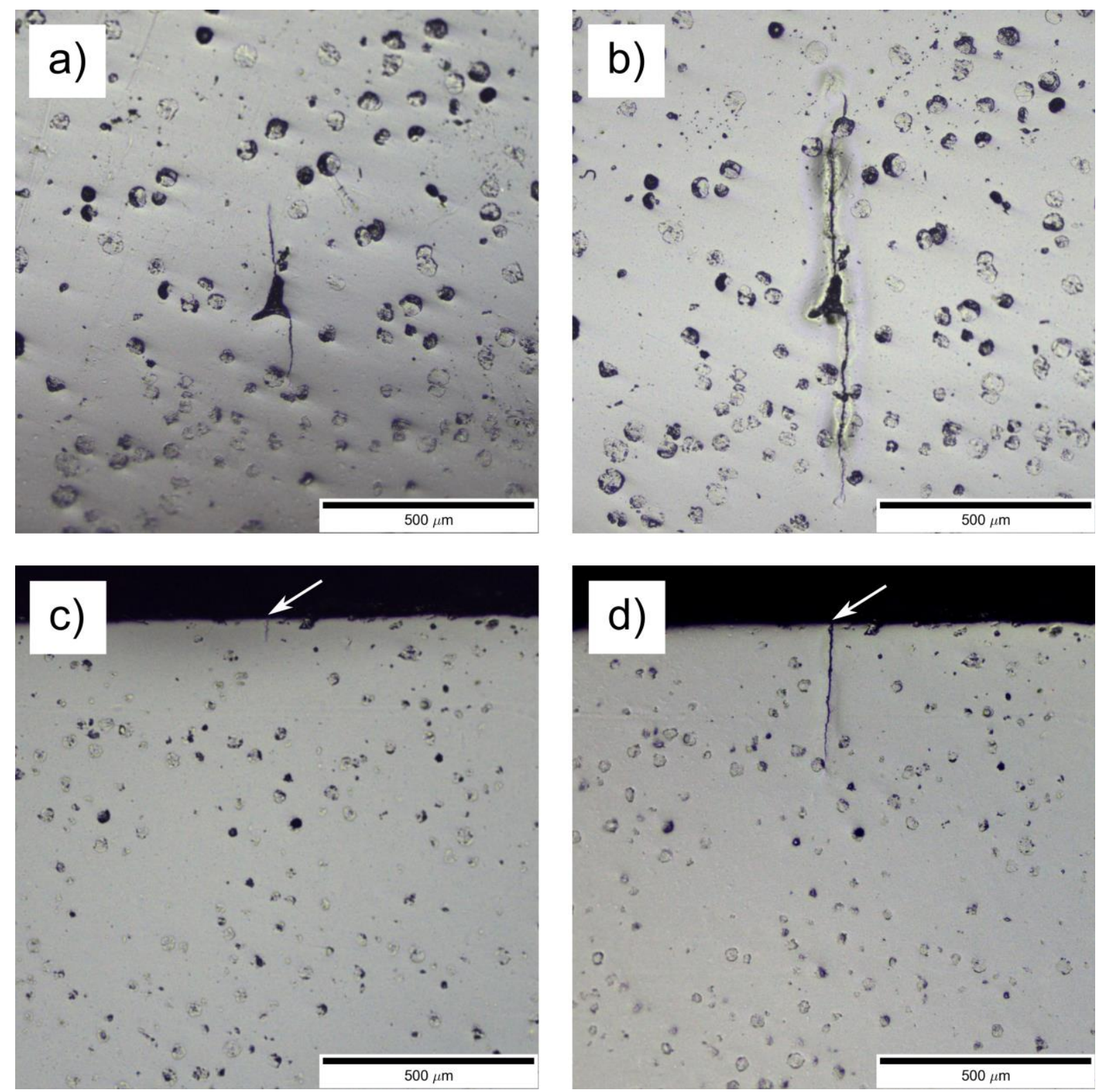

Figure 9: (a)(b) Replica record of 140/375 condition (applied stress $600 \mathrm{MPa}$ ) showing crack initiation at a pore, (c)(d) replica record of 170/375 condition (applied stress $600 \mathrm{MPa}$ ) showing crack initiation at the edge of the sample. 

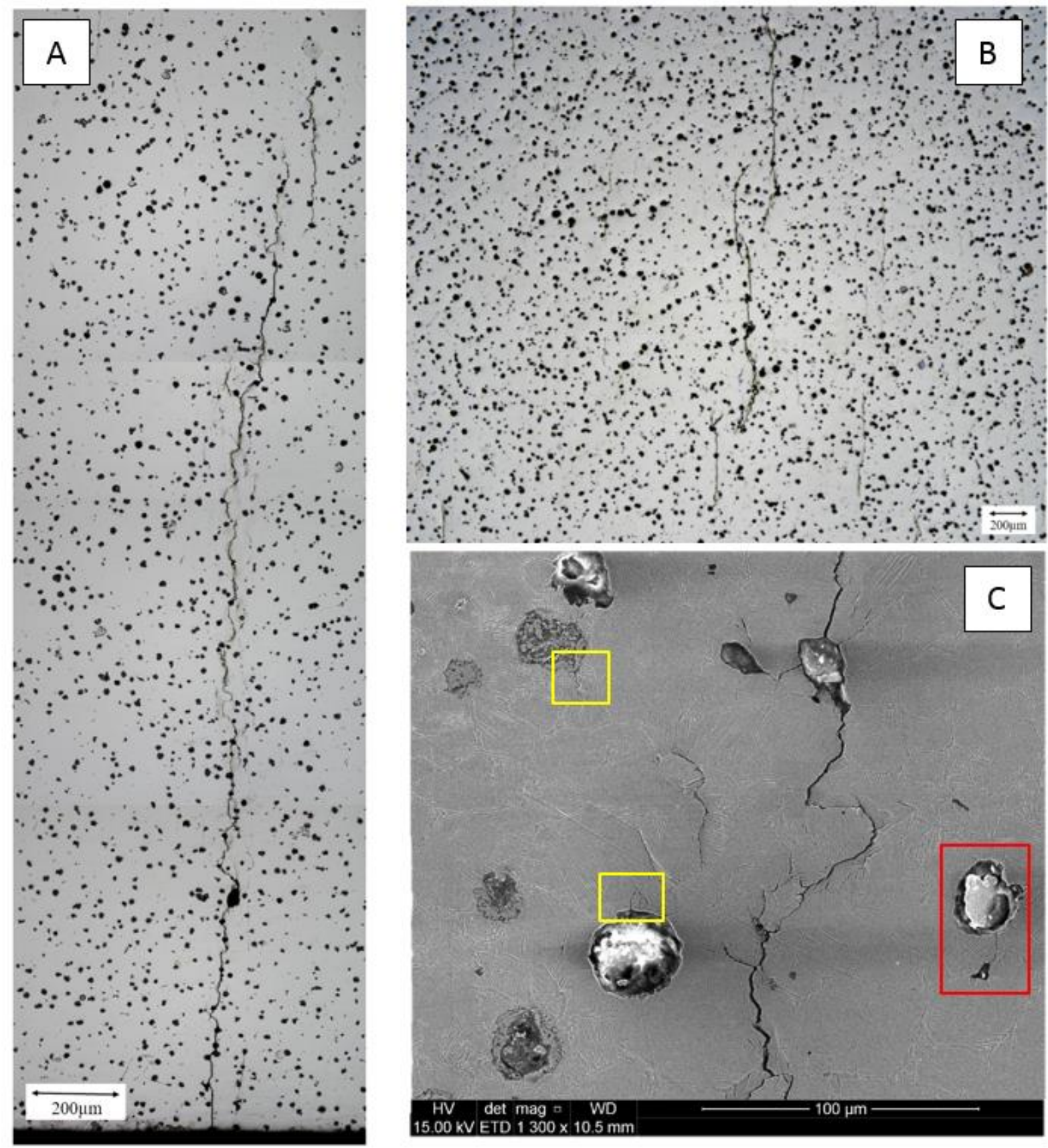

Figure 10: Crack propagation through 170/375 condition with applied stress of (a) 700 MPa and (b) 800 MPa showing coalescence of some cracks. (c)Crack propagation through 140/375 condition with applied stress of $700 \mathrm{MPa}$. Significant tortuosity can be seen in the main crack, probably due to coalescence. Also shown: arrested cracks around graphite nodules (yellow box) and possible initiation at a casting defect (red box).

In general, it is known that stress concentrations ahead of an advancing crack can lead to the formation of martensite in ferrous alloys with austenite content. Consider a fatigue sample where a crack is surrounded by a zone of austenite. As proposed by Panneerselvam et al. [29] in their work on the stability of austenite in ADI, as the crack propagates, the crack tip stresses also induce a transformation of the austenite into martensite ahead of the advancing crack tip. Thus, a portion of the energy macroscopically supplied to the sample during fatigue testing is used up for the austenite to martensite transformation. Furthermore, this transformation produces compressive stresses on the crack tip which must be overcome to propagate the crack. Panneerselvam et al. showed that if a high volume fraction of mechanically-unstable austenite can be produced in ADI, then it will be possible to 

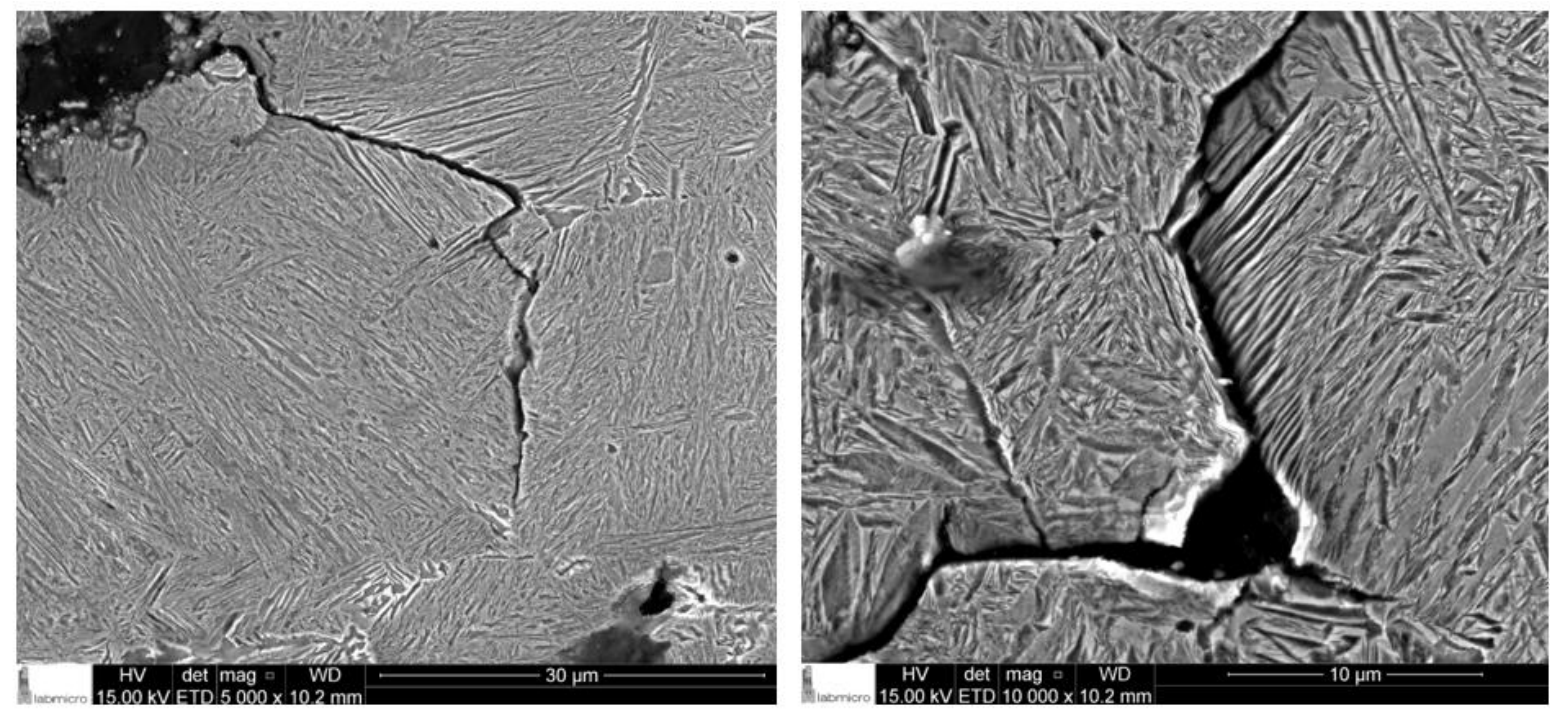

Figure 11: Crack propagation through Widmanstätten ferrite in various samples: (a) 140/375 and (b) 170/300 both at an applied stress of $700 \mathrm{MPa}$.
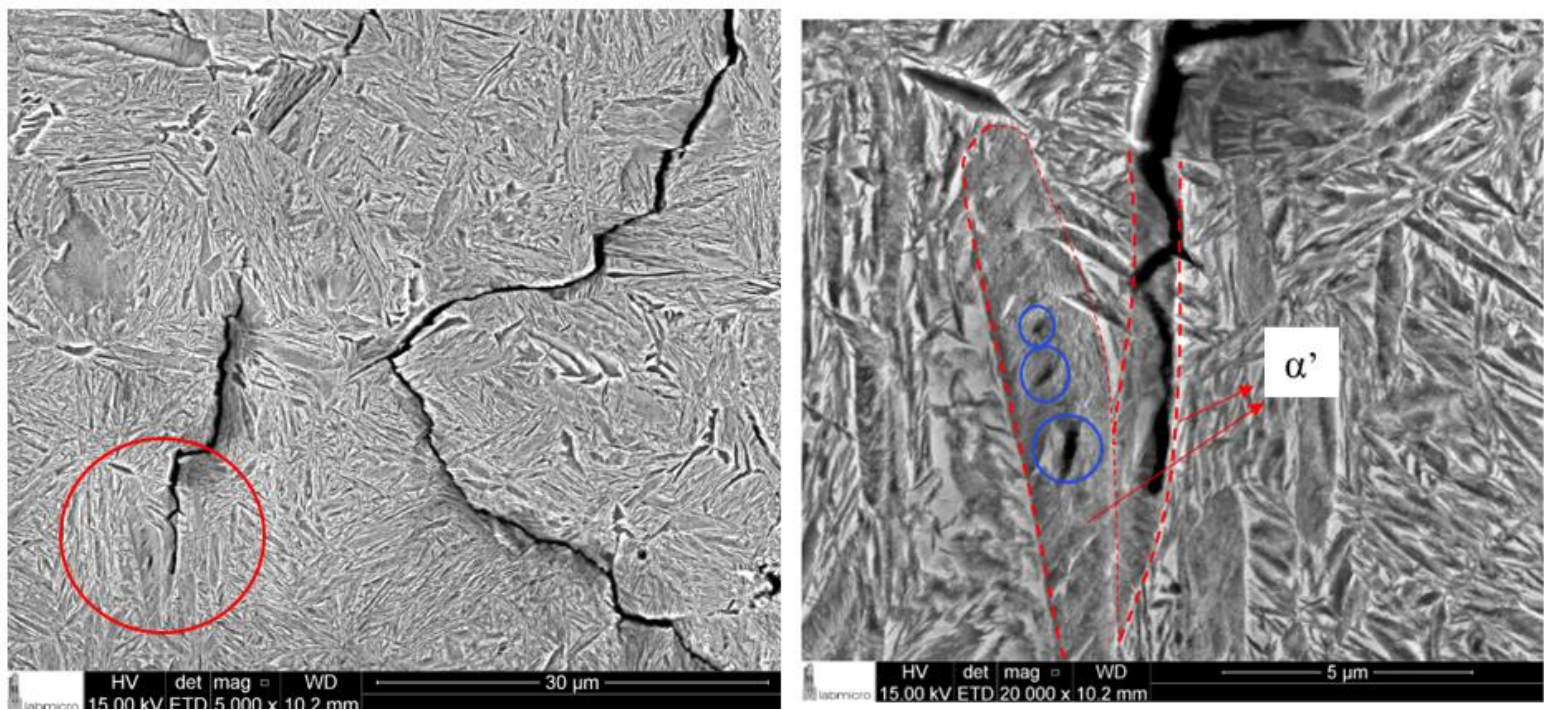

Figure 12: Crack initiation and propagation in martensite for the 170/300 sample with applied stress of 700 MPa. $\alpha^{\prime}=$ martensite.

improve both the strength properties and the fracture resistance in ADI. Stokes et al. [9] postulated that it was the crack path tortuosity due to the retained austenite that helped to explain the increased crack growth resistance of some austempers.

In this work, whilst we have shown that the fatigue limit does scale with increased retained austenite (in the Q\&PDIs), the highest fatigue limit (and retained austenite level) has not simply translated into improved short crack growth resistance in the 170/375 heat treatment, this may be due to the fact the crack coalescence events and the proximity of other cracks may be more dominant effects. Long crack growth tests are planned to allow an assessment of a more averaged crack propagation process 


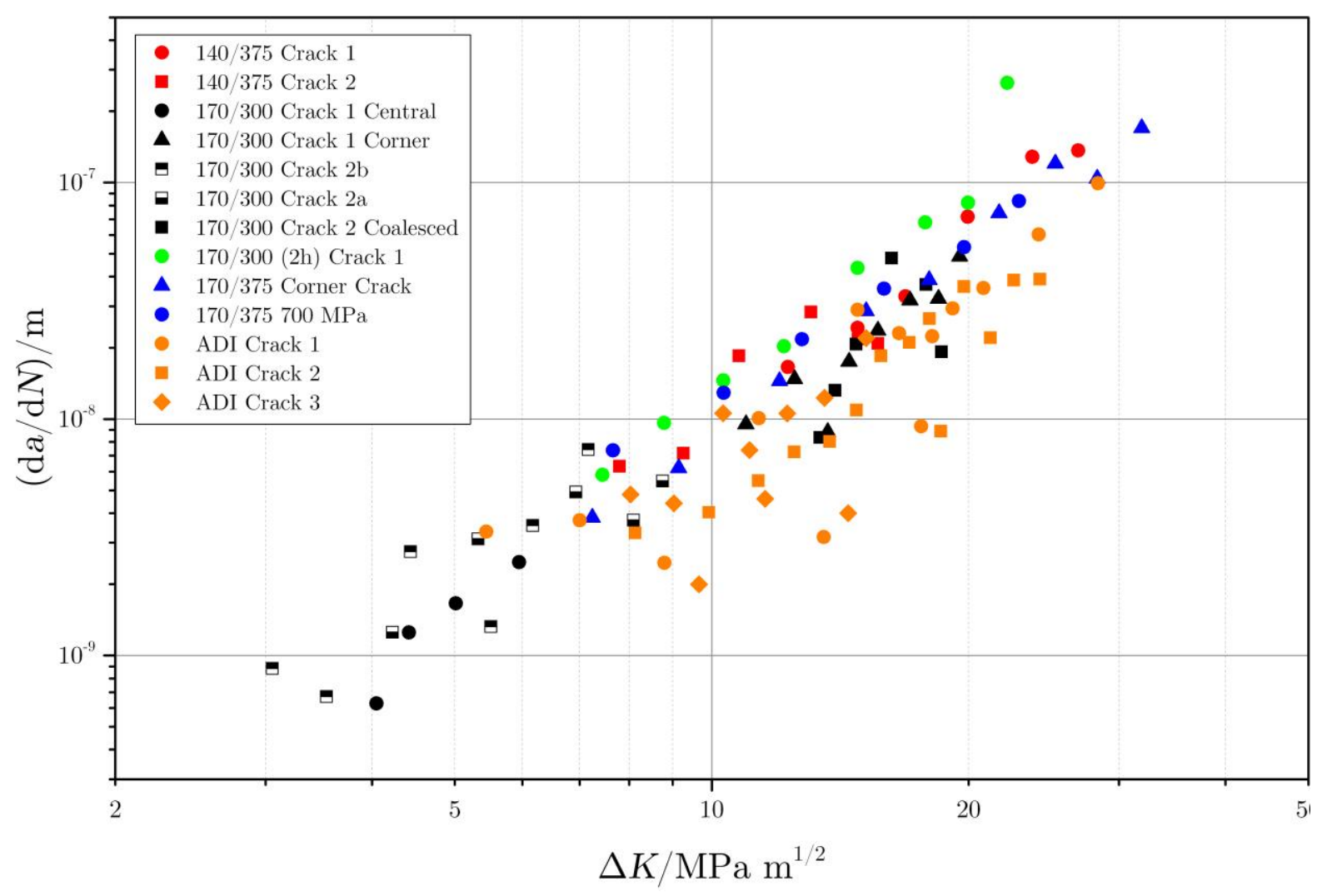

Figure 13: Crack growth rates for the Q\&PDIs tested at a maximum surface stress of 600 MPa (unless stated otherwise) and the ADI tested at a maximum surface stress of $800 \mathrm{MPa}$.
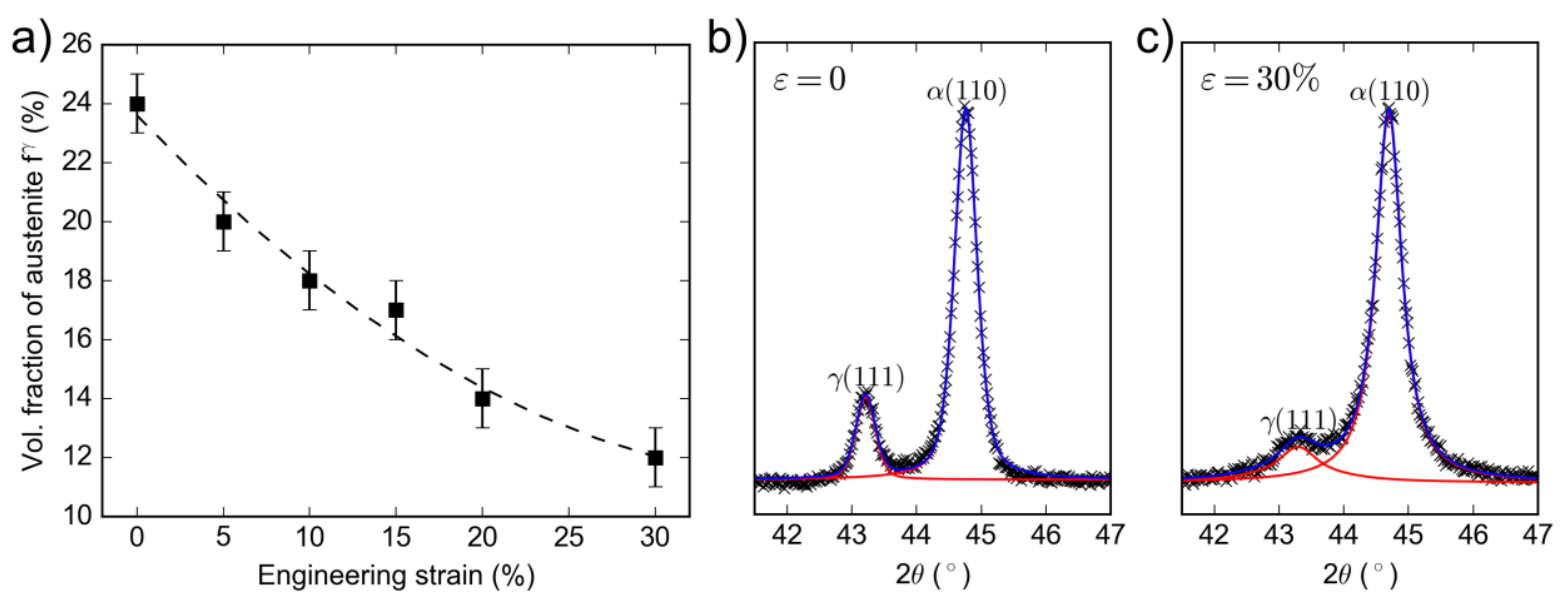

Figure 14: (a) Volumetric fraction of austenite against length reduction. (b) Profile fitting diffraction peaks for the sample without deformation (left) and 30\% of length reduction (right).

in these microstructures in terms of threshold behaviour, the Paris regime and at high crack growth rates (when monotonic failure modes may also come into play).

The 170/375 replica record in fact appeared to show a significantly longer initiation life than the other samples. Indeed, the presence of a crack was only observed on the replica taken after 215000 cycles, which exceeded the fatigue lives of the other conditions (between around 60000-90000 cycles) let alone the initiation life (typically under 20000 cycles). However, in this case initiation is simply taken as when the crack is visible on a replica, typically the cracks would be around $100 \mu \mathrm{m}$ long when they 
are first observed, the smallest was $34 \mu \mathrm{m}$. The key to the improved fatigue limit may then lie in the factors controlling initiation rather than crack propagation resistance.

To further assess the stability of the retained austenite in the 170/375 condition, plastic deformation of a cylindrical sample $(10 \times 20 \mathrm{~mm})$ by compression testing in the range of $5.0-30 \%$ length reduction, was performed to evaluate the mechanical stability of austenite. Figure 14 shows the reduction of volumetric fraction of austenite due to strain-induced martensite with increase of deformation. The reduction of (111) austenite diffraction peak for the sample with $30 \%$ of length reduction can be seen in Figure 14. This indicates that austenite transformation to martensite will occur in this heat treatment and may contribute to fatigue crack growth processes.

\section{Conclusions}

- The high strength presented by Q\&PDI compared to ADI of the same composition and nodule count is due to the presence of martensite and a much more refined microstructure.

- Allowing for the changes in yield strength, the 170/375 condition has the best fatigue performance of the Q\&PDIs due to having the largest amount of retained austenite.

- The effect of retained austenite on the total life performance of the different Q\&PDI conditions is small for the tested conditions when compared on the basis of applied nominal stress. However, when the applied stress is normalised by each condition's yield stress, it appears that the retained austenite fraction does influence the results. This suggests that the retained austenite phase may more effectively accommodate plastic strain, which would be expected if a local transformation effect was occurring.

- The performance of the $170 / 300$ condition did not follow the trends described above. The formation of untempered martensite observed in the 170/300 condition due to reduced carbon content resulted in the relatively poor fatigue lifetime performance. On increasing the partitioning time, the resulting increase in austenite carbon content prevented the formation of untempered martensite.

- Short crack growth involves a complex series of crack coalescences and prior austenite grain boundaries are shown to be more susceptible to crack propagation due to the suspected presence of Widmanstätten ferrite.

- The martensite phase also appeared to act as a favourable region for the nucleation and propagation of dominant cracks.

\section{Acknowledgements}

The authors gratefully acknowledge financial support from CNPq (National Counsel of Technological and Scientific Development) and the EPSRC (Engineering and Physical Sciences Research Council) (EP/L01582X/1).

\section{Data Access Statement}

Data sets for Figures 7, 8 and 13 are available from the University of Southampton Institutional repository https://doi.org/10.5258/SOTON/D0194. 


\section{References}

[1] J. G. Speer, D. K. Matlock, B. C. de Cooman and J. G. Schroth, "Carbon partitioning into austenite after martensite transformation," Acta Materialia, vol. 51, no. 9, pp. 2611-2622, 2003.

[2] A. J. Clarke, J. G. Speer, M. K. Miller, R. E. Hackenberg, D. V. Edmonds, D. K. Matlock, F. C. Rizzo, K. D. Clarke and E. De Moor, "Carbon partitioning from martensite to bainite during the quench and partition (Q\&P) process: A critical assessment," Acta Materialia, vol. 56, no. 1, pp. 16-22, 2008.

[3] D. V. Edmonds, K. He, F. C. Rizzo, B. C. De Cooman, D. K. Matlock and J. G. Speer, "Quenching and partitioning martensite-a novel steel heat treatment," Materials Science and Engineering: A, Vols. 438-440, pp. 25-34, 2006.

[4] A. J. S. T. Silva, H. Goldenstein, W. L. Guesser and M. F. Campos, "Quenching and partitioning heat treatment in ductile cast irons," Materials Research, vol. 17, no. 5, pp. 1114-1123, 2014.

[5] A. J. S. T. Silva, M. F. Campos, A. S. Nishikawa, W. L. Guesser and H. Goldenstein, "Quenching and partitioning heat treatment in ductile cast irons," in Proceedings of the 10th International Symposium on the Science and Processing of Cast Irons, Mar del Plata, Argentina, 2014.

[6] A. C. Melado, E. A. Viera, A. Nishikawa and H. Goldenstein, "Quenching \& partitioning heat treatment on a ductile iron: competition between martensite/austenite carbon partition and bainite reaction-mechanical properties," in International Conference on Solid-Solid Phase Transformation in Inorganic Materials, Whistler, Canada, 2015.

[7] A. C. Melado, E. A. Viera, R. K. Fujioka, A. Nishikawa and H. Goldenstein, "Influence of retained austenite in the mechanical properties of a ductile cast iron submitted to the quenching and partitioning process," in 70th International Conference of ABM, Rio de Janeiro, Brazil, 2015.

[8] A. Nishikawa, A. C. Melado, E. A. Ariza, A. P. Tschiptschin and H. Goldenstein, "Quenching and partitioning on ductile cast irons," in TMS 2016-145th TMS Annual Meeting and Exhibition, Nashville, USA, 2016.

[9] B. Stokes, N. Gao and P. A. S. Reed, "Effects of graphite nodules on crack growth behaviour of austempered ductile iron," Materials Science and Engineering: A, vol. 445, pp. 374-385, 2007.

[10] S. K. Putatunda, S. Kesani, R. Tackett and G. Lawes, "Development of austenite free ADI (austempered ductile cast iron)," Materials Science and Engineering: A, vol. 435, pp. 112-122, 2006.

[11] P. Prasad Rao and S. Putatunda, "Influence of Microstructure on Fracture Toughness of Austempered Ductile Iron," Metallurgical and Materials Transactions A, vol. 28, pp. 1457--1470, 1997.

[12] I. de Diego-Calderón, P. Rodriguez-Calvillo, A. Lara, J. M. Molina-Aldareguia, R. H. Petrov, D. De Knijf and I. Sabirov, "Effect of microstructure on fatigue behaviour of advanced high strength 
steels produced by quenching and partitioning and the role of retained austenite," Materials Science and Engineering: A, vol. 641, pp. 215-224, 2015.

[13] P. Shanmugam, P. Prasad Rao, K. Rajendra Udupa and N. Venkataraman, "Effect of microstructure on the fatigue strength of an austempered ductile iron," Journal of Materials Science, vol. 29, pp. 4933-4940, 1994.

[14] C. Y. Huo and H. L. Gao, "Strain-induced martensitic transformation in fatigue crack tip zone for a high strength steel," Materials Characterization, vol. 55, pp. 12-18, 2005.

[15] C.-K. Lin, P.-K. Lai and T.-S. Shih, "Influence of microstructure on the fatigue properties of austempered ductile irons-I. High-cycle fatigue," International Journal of Fatigue, vol. 18, no. 5, pp. 297-307, 1996.

[16] X. Cheng, R. Petrov, L. Zhao and M. Janssen, "Fatigue crack growth in TRIP steel under positive R-ratios," Engineering Fracture Mechanics, vol. 75, pp. 739-749, 2008.

[17] T. Hilditch, H. Beladi, P. Hodgson and N. Stanford, "Role of microstructure in the low cycle fatigue of multi phase steels," Materials Science and Engineering: A, vol. 534, pp. 288-296, 2012.

[18] G. N. Haidemenopoulos, A. T. Kermanidis, C. Malliaros, H. H. Dickert, P. Kucharzyk and W. Bleck, "On the effect of austenite stability on high cycle fatigue of TRIP 700 steel," Materials Science and Engineering: A, vol. 573, pp. 7-11, 2013.

[19] J. Chiang, B. Lawrence, J. D. Boyd and A. K. Pilkey, "Effect of microstructure on retained austenite stability and work hardening of TRIP steels," Materials Science and Engineering: A, vol. 528, pp. 4516-4521, 2011.

[20] A. Basuki and E. Aernoudt, "Influence of rolling of TRIP steel in the intercritical region on the stability of retained austenite," Journal of Materials Processing Technology, Vols. 89-90, pp. 3743, 1999.

[21] I. B. Timokhina, P. Hodgson and E. Pereloma, "Effect of microstructure on the stability of retained austenite in transformation-induced-plasticity steels," Metallurgical and Materials Transactions A, vol. 35, no. 8, pp. 2331-2341, 2004.

[22] D. Kostinen and R. Marburger, "A general equation prescribing the extent of the austenitemartensite transformation in pure iron-carbon alloys and plain carbon steels," Acta Metallurgica, vol. 7, no. 1, pp. 59--60, 1959.

[23] B. D. Cullity and S. R. Stock, Elements of X-Ray Diffraction, 3rd ed., Prentice Hall, 2001.

[24] D. J. Dyson and B. Holmes, "Effect of alloying additions on the lattice parameter of austenite," Journal of the Iron and Steel Institute, vol. 208, pp. 469-474, 1970.

[25] J. R. Yang and L. C. Chang, "The effect of stress on the Widmanstätten ferrite transformation," Materials Science and Engineering: A, vol. 223, pp. 158-167, 1997.

[26] P. M. Scott and T. W. Thorpe, "A critical review of crack tip stress intensity factors for semielliptic cracks," Failure of Engineering Materials and Structures, vol. 4, no. 4, pp. 291-304, 1981. 
[27] J. C. Newman and I. S. Raju, "Stress-intensity factor equations for cracks in three dimensional finite bodies subjected to tension and bending loads," in Computational Methods in the Mechanics of Fracture, S. N. Atluri, Ed., Amsterdam, Elsevier, 1986, pp. 311-334.

[28] B. He, K. Soady, B. Mellor, G. Harrison and P. Reed, "Fatigue crack growth behaviour in the LCF regime in a shot peened steam turbine material," International Journal of Fatigue, vol. 82, pp. 280--291, 2016.

[29] S. Panneerselvam, C. J. Martis, S. K. Putatunda and J. M. Boileau, "An investigation on the stability of austenite in Austempered Ductile Iron (ADI)," Materials Science and Engineering: A, vol. 626, pp. 237-246, 2015.

[30] W. L. Guesser, Propriedades mecanicas dos ferros fundidos [Mechanical properties of cast irons], São Paulo: Edgar Blucher Ltda, 2009. 